\title{
Bilirubin Can Be Used as a Prognostic Factor for Lung Adenocarcinoma Patients with EGFR Mutations
}

This article was published in the following Dove Press journal: OncoTargets and Therapy

\author{
Yimeng Geng',* \\ Yeling Mei ${ }^{1} *$ \\ Ying $X^{2}$ \\ Junlin $\mathrm{Yu}^{\prime}$ \\ Ke Meng' \\ Tengfei Zhang' \\ Wang $\mathrm{Ma}^{\prime}$
}

'Department of Oncology, The First Affiliated Hospital of Zhengzhou University, Zhengzhou, Henan, People's Republic of China; ${ }^{2}$ Department of Radiotherapy, Puyang Oilfield General Hospital, Puyang, Henan, People's Republic of China

*These authors contributed equally to this work
Correspondence: Wang Ma;

Tengfei Zhang

Email doctormw@zzu.edu.cn;

zhangtengfei84@I63.com
Background and Objectives: Non-small cell lung cancer (NSCLC) patients with an epidermal growth factor receptor $(E G F R)$ mutation demonstrate only a median progressionfree survival (PFS) of 8 to 10 months and undergo EGFR tyrosine kinase inhibitors (EGFRTKIs) therapy. For decades, bilirubin has been reported to be associated with the onset and prognosis of lung cancer as a prooxidant. This study aimed to investigate the prediction of pretreatment circulating bilirubin for PFS in lung adenocarcinoma (LAC) patients who underwent EGFR-TKIs targeted therapy.

Patients and Methods: LAC cases diagnosed and undergone EGFR-TKIs targeted therapy at The First Affiliated Hospital of Zhengzhou University between 2013 and 2015 were retrospectively reviewed. A total of 180 patients were studied according to inclusion and exclusion criteria. Follow-up data were collected for all patients until the disease progressed.

Results: Univariate analysis showed that the levels of pretreatment total bilirubin (TBIL), indirect bilirubin (IBIL) and direct bilirubin (DBIL) were related to PFS (all $p<0.05$ ). Considering the close relationship among the three factors, we combined TBIL, IBIL and DBIL into one total factor, which is called bilirubin. Kaplan-Meier survival curves and Log rank tests indicated that patients with lower bilirubin levels had a shorter median PFS than those with higher bilirubin levels ( 8 vs. 15 months; $p=0.002$ ). Multivariate analysis demonstrated that pretreatment bilirubin is an independent prognostic factor $(\mathrm{HR}=0.454$, CI: $0.267-0.773$, $p=0.004$ ).

Conclusion: This study confirms that bilirubin can predict the prognosis of LAC patients who had undergone EGFR-TKIs targeted therapy.

Keywords: bilirubin, lung adenocarcinoma, EGFR-TKIs, progression-free survival, prognosis

\section{Introduction}

Lung cancer is the leading cause of cancer-related mortality worldwide, resulting in more than 1.5 million deaths every year. ${ }^{1,2}$ Approximately $85 \%$ of all cases of lung cancer are characterised as non-small cell lung cancer (NSCLC), and lung adenocarcinoma (LAC) is the most common subtype of NSCLC. ${ }^{3,4}$ Many lung cancers are advanced at the initial diagnosis, and recent advances in chemotherapy and targeted therapy have provided new treatment options for this disease. Specifically, NSCLC patients with activating epidermal growth factor receptor (EGFR) mutations are sensitive to small-molecule EGFR tyrosine kinase inhibitors (EGFR-TKIs). ${ }^{5,6}$ These drugs have been recommended as the first-line regimen with dramatic tumour 
regression and progression-free survival (PFS) advantages compared with chemotherapy for patients in the advanced stages of lung cancer. ${ }^{7-10}$

However, most patients with NSCLC have acquired resistance to TKIs. ${ }^{11}$ There is increasing evidence that several molecular biomarkers, such as EGFR mutations, ${ }^{12}$ EGFR gene copy numbers, ${ }^{13}$ and $K$-ras gene mutations, ${ }^{14}$ are related to the prognosis of EGFR-TKIs targeted therapy. In general, these molecular biomarkers cannot be found in tissue samples until resistance has developed. Therefore, it is impossible to predict the prognosis in advance to consider intervention measures in a timely manner. Biological, clinical, and pathological factors, such as sex, smoking status, and race, are simple to obtain and can predict prognosis. ${ }^{5,15}$ Therefore, we speculated whether simple and promising clinical factors could precisely predict the prognosis of NSCLC patients receiving EGFR-TKIs targeted therapy.

Many laboratory markers, such as c-reactive protein (CRP), the neutrophil-to-lymphocyte ratio (NLR), the platelet-to-lymphocyte ratio (PLR) and monocyte counts, have been extensively discovered to play a significant role in influencing the prognosis of various types of tumours. ${ }^{16-20}$ Haematological indicators from routine testing are not only economical but also readily available for repeated testing. In this study, we investigated the prognostic value of several laboratory parameters for patients with LAC who received EGFR-TKIs targeted therapy.

\section{Patients and Methods}

\section{Patients}

We conducted a retrospective analysis of patients diagnosed with LAC who had undergone EGFR-TKIs targeted therapy at The First Affiliated Hospital of Zhengzhou University between January 2013 and December 2015. All the patients met the following criteria: pathological confirmation of LAC, advanced tumour or recurrence (had surgery or chemoradiotherapy at least 6 months prior); EGFR mutationpositive and received EGFR-TKIs targeted therapy; at least one assessable lesion; completed clinical information; provided imaging examination and laboratory data. Patients with incomplete follow-up data, brain metastases, liver metastases or a predicted survival of less than three months were excluded. The research was supported by the Ethics Committee of The First Affiliated Hospital of Zhengzhou University. We obtained consent and signed informed consent from the study participants before the study began. All the study participants agreed to the publication of this paper.

\section{Data Collection}

The detailed clinical characteristics, including gender, age, the drug types of EGFR-TKIS, state of treatment (initial treatment or recurrence), laboratory variables, and imaging materials, were obtained. Disease stage was based on the 8th edition of the TNM classification of malignant tumours. ${ }^{21}$ Blood samples were taken before treatment with EGFRTKIs. Based on this, five haematology indexes of laboratory variables, including alanine transaminase (ALT), aspartate transaminase (AST), total bilirubin (TBIL), direct bilirubin (DBIL), indirect bilirubin (IBIL), were extracted retrospectively from the medical records. Hematological indexes were divided into several groups based on quartile values, and then a cut-off point with the best significance in survival analysis was selected. At last, patients were divided into two groups with levels over and under the value. Patient progression outcomes were assessed using PFS, the period from the date of treatment to relapse or progression. Based on the Response Evaluation Criteria in Solid Tumours (RECIST, version 1.1) guidelines, ${ }^{22,23}$ the response was assessed by computed tomography (CT) once every two months or a CT scan of the patients after discomfort.

\section{Statistical Analysis}

All statistical analyses were performed using SPSS version 17.0 software (SPSS, Inc., Chicago, Ill). Continuous variables were described using medians (range) or mean $\pm \mathrm{SD}$, and categorical variables were given as absolute numbers (percentage values). Chi-squared test was used for comparative analysis of categorical variables, and Student's $t$-test was used for continuous variables. The cumulative survival curve and median PFS time were estimated by the Kaplan-Meier method. Differences between survival curves were tested for statistical significance using the two-tailed Log rank test. Multivariate prognostic analyses were performed for PFS using the Cox proportional hazards model. A two-tailed $p<0.05$ was considered to indicate a statistically significant difference.

\section{Results}

\section{Patient Characteristics}

Finally, 180 patients were recruited into the study according to the inclusion and exclusion criteria. In total, 69 patients (38.3\%) were men and 111 patients $(61.7 \%)$ were women. The median age at the time of therapy was 59 years (range: 30-85 years). Among them, 149 patients were treated with oral gefitinib, and 31 were treated with oral erlotinib. The 
Table I Baseline Clinicopathological Characteristics of Patients

\begin{tabular}{|l|l|}
\hline Characteristics & Total $(\mathbf{N}=\mathbf{~ 1 8 0})$ \\
\hline Age (median, range), years & $59(30$ to 85$)$ \\
Gender (Male/Female) & $69 / I I I$ \\
State of treatment (initial/recurrence) & $138 / 42$ \\
Drugs (Gefinitib/erlotinib) & $149 / 3 \mathrm{I}$ \\
ALT (mean \pm SD), U/L & $23.750 \pm 20.212$ \\
AST (mean \pm SD), U/L & $23.360 \pm 13.202$ \\
TBIL (mean \pm SD), $\mu \mathrm{mol} / \mathrm{L}$ & $9.410 \pm 5.004$ \\
DBIL (mean \pm SD), $\mu \mathrm{mol} / \mathrm{L}$ & $4.030 \pm 2.136$ \\
IBIL (mean \pm SD), $\mu \mathrm{mol} / \mathrm{L}$ & $5.380 \pm 3.180$ \\
\hline
\end{tabular}

Abbreviations: SD, standard deviation; ALT, alanine transaminase; AST, aspartate transaminase; TBIL, total bilirubin; IBIL, indirect bilirubin; DBIL, direct bilirubin.

baseline clinicopathological characteristics and information of these patients are summarised in Table 1.

\section{Survival Analysis}

In this study, the median duration of follow-up for the PFS time was 7.0 months (range, 0.5 to 51). The median PFS was 14.0 months. At the time of the data cut-off, an event of RECIST-defined progression had occurred in 78 patients (43.3\%), and the remaining $102(56.7 \%)$ manifested as disease stabilisation or remission.

Univariate analysis was performed to determine the clinicopathologic characteristics that had a relationship with PFS. The results suggested that TBIL $(p=0.003)$, IBIL $(p=0.008)$ and DBIL $(p=0.027)$ were correlated with PFS. Nevertheless, age, gender, EGFR-TKIs drugs, state of treatment, ALT and AST were not statistically significant in predicting PFS $(p>0.05)$ (Table 2). The Log rank test and Kaplan-Meier survival curves indicated that patients with lower levels of TBIL $<6.2 \mu \mathrm{mol} / \mathrm{L}, \mathrm{IBIL}<3.2 \mu \mathrm{mol} / \mathrm{L}$, and $\mathrm{DBIL}<3.55 \mu \mathrm{mol} / \mathrm{L}$ had shorter median survival times than those with higher levels (Figure 1). Considering the interaction of the three kinds of bilirubin in vivo, we analysed their correlation, and the results showed that the three kinds of bilirubin were linearly correlated (Figure 2). Patients with lower levels of TBIL, IBIL, and DBIL were grouped into one group as the lower group, and the rest were the higher group. We incorporated bilirubin into the Log rank test and found that patients in the lower group had a worse prognosis than patients in the higher group ( 8 vs. 15 months; $p=0.002$ ), as shown in Figure 3. The results of multivariate analysis among clinical characteristics and laboratory variables showed that bilirubin $(p=0.004)$ was an independent prognostic factor to predict PFS (Table 3). Our results revealed that bilirubin is an independent prognostic factor for PFS.
Table 2 Log Rank Test of Significant Indicators in Lung Adenocarcinoma Patients

\begin{tabular}{|c|c|c|c|}
\hline Characteristics & $\begin{array}{l}\text { Median PFS. Months } \\
(95 \% \mathrm{Cl})\end{array}$ & $\begin{array}{l}\text { Chi- } \\
\text { Square }\end{array}$ & $p$-value \\
\hline $\begin{array}{l}\text { Age, years } \\
\quad<65 \\
\geq 65\end{array}$ & $\begin{array}{l}\text { II }(6.319-15.681) \\
\text { I5 (II.108-18.892) }\end{array}$ & 0.422 & 0.516 \\
\hline $\begin{array}{l}\text { Gender } \\
\text { Male } \\
\text { Female }\end{array}$ & $\begin{array}{l}16(10.49 \mid-21.509) \\
12(8.230-15.770)\end{array}$ & 0.035 & 0.851 \\
\hline $\begin{array}{l}\text { State of } \\
\text { treatment } \\
\text { Initial } \\
\text { Recurrence }\end{array}$ & $\begin{array}{l}\text { I5 (I0.945-I8.245) } \\
\text { I2 (8.I54-I5.846) }\end{array}$ & 1.218 & 0.270 \\
\hline $\begin{array}{l}\text { Drugs } \\
\text { Gefinitib } \\
\text { Erlotinib }\end{array}$ & $\begin{array}{l}\text { I2 (8.274-I5.726) } \\
\text { II (0.199-2I.80I) }\end{array}$ & 0.091 & 0.762 \\
\hline $\begin{array}{l}\text { TBIL, } \mu \mathrm{mol} / \mathrm{L} \\
\quad<6.2 \\
\geq 6.2\end{array}$ & $\begin{array}{l}8(5.650-10.350) \\
15(10.570-19.440)\end{array}$ & 8.713 & 0.003 \\
\hline $\begin{array}{l}\text { IBIL, } \mu \mathrm{mol} / \mathrm{L} \\
\quad<3.2 \\
\quad \geq 3.2\end{array}$ & $\begin{array}{l}8(6.400-9.600) \\
15(11.300-18.700)\end{array}$ & 7.005 & 0.008 \\
\hline $\begin{array}{l}\text { DBIL, } \mu \mathrm{mol} / \mathrm{L} \\
\quad<3.55 \\
\quad \geq 3.55\end{array}$ & $\begin{array}{l}10(7.000-13.000) \\
16(10.930-21.070)\end{array}$ & 4.893 & 0.027 \\
\hline
\end{tabular}

Abbreviations: PFS, progression-free survival; $\mathrm{Cl}$, confidence interval; TBIL, total bilirubin; IBIL, indirect bilirubin; DBIL, direct bilirubin.

\section{Association Between Bilirubin and Clinicopathologic Variables}

We analyzed the relationship between bilirubin and ALT, AST and other clinical features, to exclude the influence of confounders. $T$-test of students showed that ALT and AST were not associated with bilirubin, and the difference was not statistically significant ( $p=0.86, p=0.952$, respectively). The chi-squared test results demonstrated that the age, gender, state of treatment, drugs were not associated with bilirubin $(p>0.05)$ (Table 4).

\section{Discussion}

In recent years, bilirubin has been reported to be associated with the prognosis of cancers. Several recent studies have shown that slightly higher bilirubin levels appear to be beneficial for cancer patients. The higher is the total bilirubin level, the better is the prognosis of pancreatic cancer, ${ }^{24}$ breast cancer ${ }^{25}$ and lung cancer. ${ }^{26}$ In our study, 

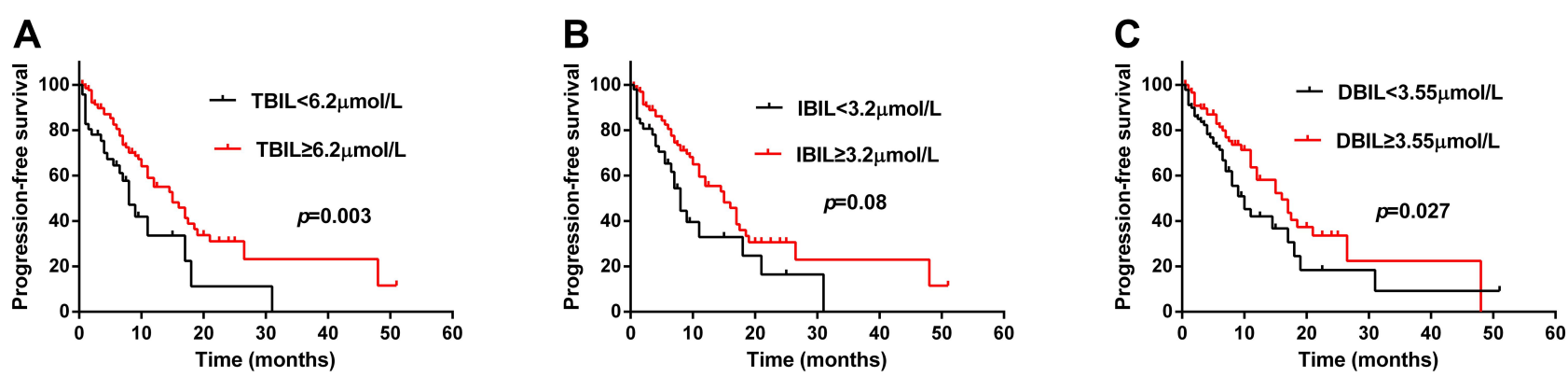

Figure I Significant differences were found in different levels of TBIL, IBIL and DBIL from the Kaplan-Meier survival curve. (A-C) Elevated pretreatment TBIL, IBIL and DBIL were significantly associated with better progression-free survival.

Abbreviations: TBIL, total bilirubin; IBIL, indirect bilirubin; DBIL, direct bilirubin.
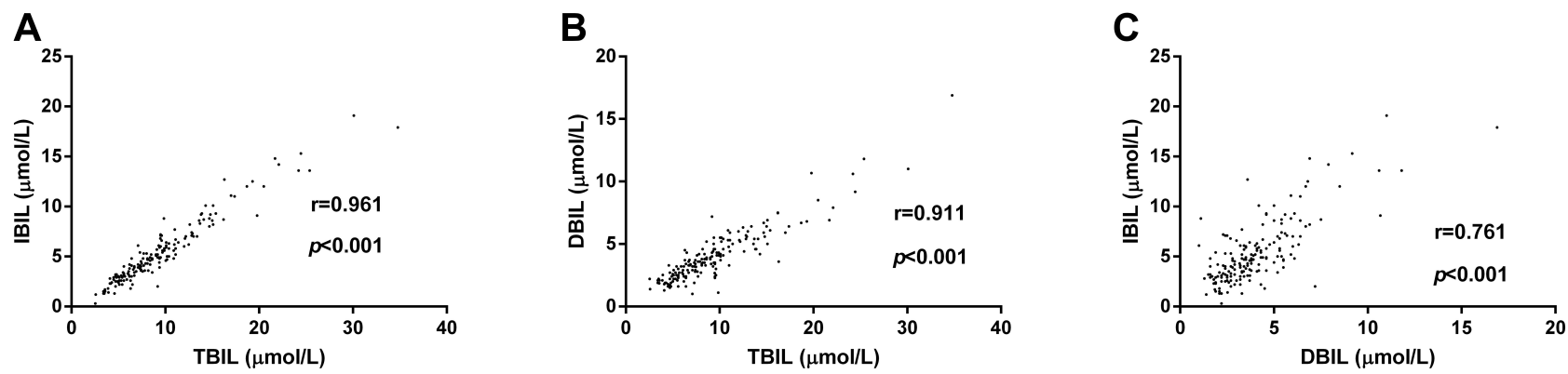

Figure 2 Scatterplot of the relationship between TBIL, IBIL and DBIL. (A, B) TBIL is linearly dependent with IBIL and DBIL ( $r=0.9 \mathrm{II} ; \mathrm{r}=0.96 \mathrm{I}$, respectively); (C) The linear relation between DBIL and IBIL is not so obvious, but still shows a linear correlation $(r=0.761 ; p<0.00 I)$.

Abbreviation: $r$, regression coefficient.

patients with higher levels of TBIL $\geq 6.2 \mu \mathrm{mol} / \mathrm{L}$, IBIL $\geq 3.2$ $\mu \mathrm{mol} / \mathrm{L}$, and DBIL $\geq 3.55 \mu \mathrm{mol} / \mathrm{L}$ had longer median survival times than those with lower levels. At the same time, the range of total bilirubin in the data we collected was $2.55-34.8 \mathrm{~mol} / \mathrm{L}$, with only three patients with abnormal levels $(\geq 25 \mu \mathrm{mol} / \mathrm{L}): 34.8 \mu \mathrm{mol} / \mathrm{L}, 30.1 \mu \mathrm{mol} / \mathrm{L}$ and 25.4 $\mu \mathrm{mol} / \mathrm{L}$. Therefore, we conclude that a higher level of

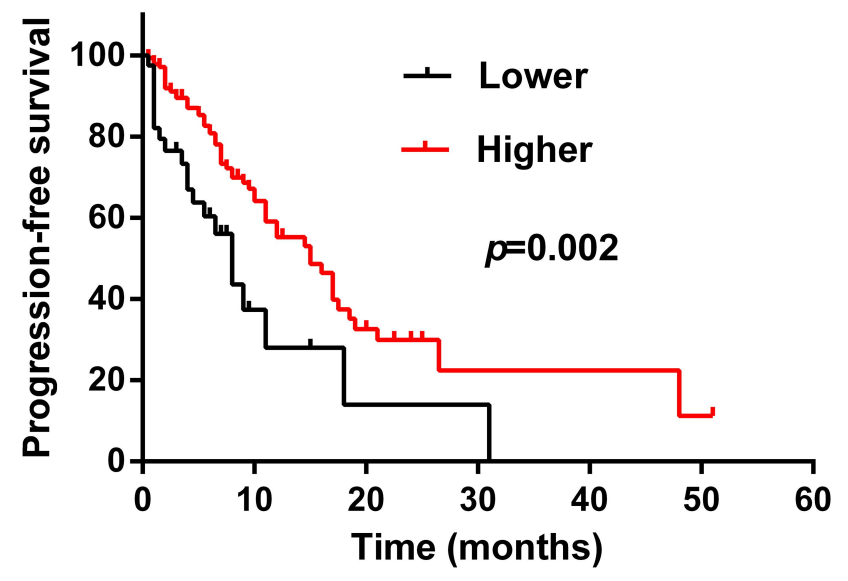

Figure 3 The Kaplan-Meier survival curve of bilirubin factor. Higher bilirubin factor was significantly associated with better progression-free survival. pretreatment bilirubin within the normal range may predict a better prognosis in LAC patients who received EGFRTKIs.

Bilirubin is the main end product of heme degradation, which can cause irreversible damage to the brain and nervous system. However, bilirubin also shows important cellular protective effects, with antioxidant ${ }^{27}$ and antiinflammatory antioxidant capacity. ${ }^{28}$ Notably, bilirubin also induces apoptosis and anti-proliferation and inhibits the growth of various tumour cells. The mechanisms by which bilirubin inhibits cell growth include the induction of oxidative stress and mitochondrial depolarisation. ${ }^{29,30}$

Table 3 Multivariate Survival Analysis in Relation to PFS in Lung Adenocarcinoma Patients

\begin{tabular}{|l|l|l|l|}
\hline Characteristics & HR & $\mathbf{9 5 \%} \mathbf{C I}$ & p-value \\
\hline Bilirubin, lower/higher & 0.454 & $0.267-0.773$ & 0.004 \\
Gender, Male/Female & 0.989 & $0.621-1.575$ & 0.963 \\
Age, $<65 / \geq 65$, years & 0.952 & $0.583-1.554$ & 0.844 \\
State of treatment (initial/ & 1.119 & $0.922-1.358$ & 0.256 \\
recurrence) & & & \\
Drugs, Gefinitib/Erlotinib & 1.188 & $0.661-2.135$ & 0.565 \\
\hline
\end{tabular}

Abbreviations: $\mathrm{HR}$, hazard ratio; $\mathrm{Cl}$, confidence interval. 
Table 4 Correlation Between Total Bilirubin and Clinical Characteristics

\begin{tabular}{|l|l|l|l|}
\hline Variables & Lower $(\mathbf{n = 4 0})$ & Higher $(\mathbf{n = 1 4 0 )}$ & p-value \\
\hline $\begin{array}{c}\text { Age, years } \\
<65\end{array}$ & $31(77.5 \%)$ & $94(67.1 \%)$ & 0.144 \\
$\geq 65$ & $9(22.5 \%)$ & $46(32.9 \%)$ & \\
\hline $\begin{array}{c}\text { Gender } \\
\text { Male }\end{array}$ & $12(30 \%)$ & $57(40.7 \%)$ & 0.219 \\
Female & $28(70 \%)$ & $83(59.3 \%)$ & \\
\hline $\begin{array}{c}\text { State of treatment } \\
\text { Initial } \\
\text { Recurrence }\end{array}$ & $29(72.5 \%)$ & $109(77.9 \%)$ & 0.480 \\
\hline $\begin{array}{c}\text { Drugs } \\
\text { Gefitinib } \\
\text { Erlotinib }\end{array}$ & $36(85 \%)$ & $113(80.7 \%)$ & 0.170 \\
\hline
\end{tabular}

Abbreviation: $\mathrm{n}$, the number of patients in each group.

In many studies, bilirubin is associated with lower tumorigenesis $^{31-33}$ and cancer mortality. ${ }^{34}$ Those with elevated bilirubin had a longer overall survival than those with normal bilirubin. Some studies have shown that serum bilirubin is a positive prognostic factor in lung cancer with strong antioxidant and antitumour effects ${ }^{26,35}$ which is consistent with ours. However, the relationship between bilirubin and lung cancer survival remains controversial. In Yanwei Zhang et al's study, direct bilirubin was identified as a prognostic risk factor for advanced NSCLC patients with EGFR mutations. ${ }^{36}$ Regarding the existence of controversy, we suspect that this difference may be due to different patient characteristics.

In our study, higher levels of bilirubin predicted a good prognosis in patients with advanced NSCLC with EGFR mutations. To our best knowledge, this is the first report showing the beneficial prognostic value of bilirubin in LAC patients who received EGFR-TKIs targeted therapy. Our research demonstrated that bilirubin ( $\mathrm{HR}=0.454, \mathrm{CI}$ : $0.267-$ $0.773, p=0.004)$ is an independent prognostic factor for PFS, and the prognosis is poor in the lower group $(p=0.002)$. When the data were collected in this study, we excluded patients with liver metastases to ensure the effect of liver function on the results. The correlation analysis between bilirubin and patient age, gender, state of treatment, drugs, ALT, AST showed no relationship between them ( $p>0.05)$; thus, we excluded their effect on the patient's bilirubin. We hypothesise that total bilirubin may be a predictor of LAC patients receiving EGFR-TKIs targeted therapy based on antioxidant, anti-inflammatory and anti-proliferative effects.
This study is a retrospective study, which inevitably has some limitations. First, like other retrospective studies, we cannot completely rule out the impact of selection bias. Second, our study include is limited by its single-centre and retrospective design. Third, China constitutes the entirety of our population sample. Our results may not apply to other ethnic populations. However, the findings of this study may help to facilitate the understanding of the relationship between the tumour microenvironment and clinical factors. Additionally, larger and more detailed prospective studies are needed to further clarify these relationships.

\section{Conclusion}

We have demonstrated that bilirubin is an independent predictor for NSCLC patients who are treated with EGFRTKIs targeted therapy. Moreover, patients with higher pretreatment serum bilirubin levels have a longer PFS than those with lower pretreatment serum bilirubin levels. Further well-designed studies with more patients and longer follow-up times are warranted to confirm the prognostic value of bilirubin levels in NSCLC, considering other potential prognostic factors for NSCLC.

\section{Acknowledgment}

This research was sponsored by Program for Science \& Technology Innovation Talents in Universities of Henan Province (19HASTIT001).

\section{Author Contributions}

Yimeng Geng and Yeling Mei are responsible for conception, study design, data analysis and interpretation, drafting the article. Ying $\mathrm{Xi}$, Junlin $\mathrm{Yu}$ and Ke Meng are responsible for acquisition of data, data analysis and interpretation, and critically revised the article. Tengfei Zhang and Wang Ma are responsible for study execution and substantially revised the article. All authors have agreed on the journal to which the article will be submitted. All authors agreed to take responsibility and be accountable for the contents of the article, reviewed and agreed on all versions of the article before submission, during revision, the final version accepted for publication, and any significant changes introduced at the proofing stage, and agreed to take responsibility and be accountable for the contents of the article.

\section{Disclosure}

The authors declare no conflicts of interest. 


\section{References}

1. Torre L, Bray F, Siegel R, Ferlay J, Lortet-Tieulent J, Jemal A. Global cancer statistics, 2012. CA Cancer J Clin. 2015;65 (2):87-108. doi:10.3322/caac.21262

2. Page G, Green J, Lackland D. Epidemiology of lung cancer with special reference to genetics, bioassays, women, and developing countries. Semin Respir Crit Care Med. 2000;21(5):365-373. doi:10.1055/s-2000-9403

3. Herbst R, Heymach J, Lippman S. Lung cancer. $N$ Engl J Med. 2008;359(13):1367-1380. doi:10.1056/NEJMra0802714

4. Oser MG, Niederst MJ, Sequist LV, Engelman JA. Transformation from non-small-cell lung cancer to small-cell lung cancer: molecular drivers and cells of origin. Lancet Oncol. 2015;16(4):e165-e172. doi:10.1016/S1470-2045(14)71180-5

5. Lynch TJ, Bell DW, Sordella R, et al. Activating mutations in the epidermal growth factor receptor underlying responsiveness of non-small-cell lung cancer to gefitinib. $N$ Engl $J$ Med. 2004;350 (21):2129-2139. doi:10.1056/NEJMoa040938

6. Zhou Q, Zhang XC, Chen ZH, et al. Relative abundance of EGFR mutations predicts benefit from gefitinib treatment for advanced non-small-cell lung cancer. J Clin Oncol. 2011;29(24):3316-3321. doi:10.1200/JCO.2010.33.3757

7. Sequist LV, Yang JC, Yamamoto N, et al. Phase III study of afatinib or cisplatin plus pemetrexed in patients with metastatic lung adenocarcinoma with EGFR mutations. J Clin Oncol. 2013;31 (27):3327-3334. doi:10.1200/JCO.2012.44.2806

8. Rosell R, Carcereny E, Gervais R, et al. Erlotinib versus standard chemotherapy as first-line treatment for European patients with advanced EGFR mutation-positive non-small-cell lung cancer (EURTAC): a multicentre, open-label, randomised Phase 3 trial. Lancet Oncol. 2012;13(3):239-246. doi:10.1016/S1470-2045(11)70393-X

9. Mok TS, Wu YL, Thongprasert S, et al. Gefitinib or carboplatin-paclitaxel in pulmonary adenocarcinoma. $N$ Engl J Med. 2009;361(10):947-957. doi:10.1056/NEJMoa0810699

10. Mitsudomi T, Morita S, Yatabe Y, et al. Gefitinib versus cisplatin plus docetaxel in patients with non-small-cell lung cancer harbouring mutations of the epidermal growth factor receptor (WJTOG3405): an open label, randomised phase 3 trial. Lancet Oncol. 2010;11 (2):121-128. doi:10.1016/S1470-2045(09)70364-X

11. Kosaka T, Yatabe Y, Endoh H, et al. Analysis of epidermal growth factor receptor gene mutation in patients with non-small cell lung cancer and acquired resistance to gefitinib. Clin Cancer Res. 2006;12 (19):5764-5769. doi:10.1158/1078-0432.CCR-06-0714

12. Mitsudomi T, Kosaka T, Endoh H, et al. Mutations of the epidermal growth factor receptor gene predict prolonged survival after gefitinib treatment in patients with non-small-cell lung cancer with postoperative recurrence. J Clin Oncol. 2005;23(11):2513-2520. doi:10.1200/ JCO.2005.00.992

13. Takano T, Ohe Y, Sakamoto $\mathrm{H}$, et al. Epidermal growth factor receptor gene mutations and increased copy numbers predict gefitinib sensitivity in patients with recurrent non-small-cell lung cancer. J Clin Oncol. 2005;23(28):6829-6837.

14. Massarelli E, Varella-Garcia M, Tang X, et al. KRAS mutation is an important predictor of resistance to therapy with epidermal growth factor receptor tyrosine kinase inhibitors in non-small-cell lung cancer. Clin Cancer Res. 2007;13(10):2890-2896. doi:10.1158/ 1078-0432.CCR-06-3043

15. Pao W, Miller VA. Epidermal growth factor receptor mutations, small-molecule kinase inhibitors, and non-small-cell lung cancer: current knowledge and future directions. J Clin Oncol. 2005;23 (11):2556-2568. doi:10.1200/JCO.2005.07.799

16. Crumley AB, McMillan DC, McKernan M, McDonald AC, Stuart RC. Evaluation of an inflammation-based prognostic score in patients with inoperable gastro-oesophageal cancer. $\mathrm{Br} J$ Cancer. 2006;94(5):637-641. doi:10.1038/sj.bjc.6602998
17. Li J, Jiang R, Liu WS, et al. A large cohort study reveals the association of elevated peripheral blood lymphocyte-to-monocyte ratio with favorable prognosis in nasopharyngeal carcinoma. PLoS One. 2013;8(12):e83069. doi:10.1371/journal.pone.0083069

18. Kim DK, Oh SY, Kwon HC, et al. Clinical significances of preoperative serum interleukin-6 and C-reactive protein level in operable gastric cancer. BMC Cancer. 2009;9:155. doi:10.1186/1471-24079-155

19. Templeton A, McNamara M, Šeruga B, et al. Prognostic role of neutrophil-to-lymphocyte ratio in solid tumors: a systematic review and meta-analysis. J Natl Cancer Inst. 2014;106(6):dju124. doi:10. 1093/jnci/dju124

20. Kumagai S, Marumo S, Shoji T, et al. Prognostic impact of preoperative monocyte counts in patients with resected lung adenocarcinoma. Lung Cancer. 2014;85(3):457-464. doi:10.1016/j. lungcan.2014.06.015

21. Detterbeck FC, Chansky K, Groome P, et al. The IASLC lung cancer staging project: methodology and validation used in the development of proposals for revision of the stage classification of NSCLC in the forthcoming (eighth) edition of the TNM classification of lung cancer. J Thorac Oncol. 2016;11(9):1433-1446. doi:10.1016/j. jtho.2016.06.028

22. Eisenhauer EA, Therasse P, Bogaerts J, et al. New response evaluation criteria in solid tumours: revised RECIST guideline (version 1.1). Eur J Cancer. 2009;45(2):228-247. doi:10.1016/j.ejca.2008.10.026

23. Bogaerts J, Ford R, Sargent D, et al. Individual patient data analysis to assess modifications to the RECIST criteria. Eur J Cancer. 2009;45 (2):248-260. doi:10.1016/j.ejca.2008.10.027

24. Haas M, Heinemann V, Kullmann F, et al. Prognostic value of CA 19-9, CEA, CRP, LDH and bilirubin levels in locally advanced and metastatic pancreatic cancer: results from a multicenter, pooled analysis of patients receiving palliative chemotherapy. J Cancer Res Clin Oncol. 2013;139(4):681-689. doi:10.1007/s00432-012-1371-3

25. Liu X, Meng QH, Ye Y, Hildebrandt MA, Gu J, Wu X. Prognostic significance of pretreatment serum levels of albumin, LDH and total bilirubin in patients with non-metastatic breast cancer. Carcinogenesis. 2015;36(2):243-248. doi:10.1093/carcin/bgu247

26. Li N, Xu M, Cai M, et al. Elevated serum bilirubin levels are associated with improved survival in patients with curatively resected non-small-cell lung cancer. Cancer Epidemiol. 2015;39(5):763-768. doi:10.1016/j.canep.2015.06.007

27. Stocker R, Yamamoto Y, McDonagh A, Glazer A, Ames B. Bilirubin is an antioxidant of possible physiological importance. Science. 1987;235(4792):1043-1046. doi:10.1126/science.3029864

28. Breimer L, Wannamethee G, Ebrahim S, Shaper A. Serum bilirubin and risk of ischemic heart disease in middle-aged British men. Clin Chem. 1995;41(10):1504-1508. doi:10.1093/clinchem/41.10.1504

29. Rao P, Suzuki R, Mizobuchi S, Yamaguchi T, Sasaguri S. Bilirubin exhibits a novel anti-cancer effect on human adenocarcinoma. Biochem Biophys Res Commun. 2006;342(4):1279-1283. doi:10. 1016/j.bbrc.2006.02.074

30. Keshavan P, Schwemberger S, Smith D, Babcock G, Zucker S. Unconjugated bilirubin induces apoptosis in colon cancer cells by triggering mitochondrial depolarization. Int J Cancer. 2004;112 (3):433-445. doi:10.1002/ijc.20418

31. Horsfall L, Rait G, Walters K, et al. Serum bilirubin and risk of respiratory disease and death. JAMA. 2011;305(7):691-697. doi:10.1001/jama.2011.124

32. Zucker S, Horn P, Sherman K. Serum bilirubin levels in the U.S. population: gender effect and inverse correlation with colorectal cancer. Hepatology. 2004;40(4):827-835. doi:10.1002/hep.1840 400412

33. Wen C, Zhang F, Liang D, et al. The ability of bilirubin in identifying smokers with higher risk of lung cancer: a large cohort study in conjunction with global metabolomic profiling. Clin Cancer Res. 2015;21(1):193-200. doi:10.1158/1078-0432.CCR-14-0748 
34. Temme E, Zhang J, Schouten E, Kesteloot H. Serum bilirubin and 10 -year mortality risk in a Belgian population. Cancer Causes Control. 2001;12(10):887-894. doi:10.1023/A:1013794407325

35. Song Y, Gao X, Hong Y, Wang L. Direct bilirubin levels are prognostic in non-small cell lung cancer. Oncotarget. 2018;9(1):892-900. doi:10.18632/oncotarget. 23184
36. Zhang Y, Xu J, Lou Y, et al. Pretreatment direct bilirubin and total cholesterol are significant predictors of overall survival in advanced non-small-cell lung cancer patients with EGFR mutations. Int $J$ Cancer. 2017;140(7):1645-1652. doi:10.1002/ijc.30581

\section{Publish your work in this journal}

OncoTargets and Therapy is an international, peer-reviewed, open access journal focusing on the pathological basis of all cancers, potential targets for therapy and treatment protocols employed to improve the management of cancer patients. The journal also focuses on the impact of management programs and new therapeutic

Submit your manuscript here: https://www.dovepress.com/oncotargets-and-therapy-journal agents and protocols on patient perspectives such as quality of life, adherence and satisfaction. The manuscript management system is completely online and includes a very quick and fair peer-review system, which is all easy to use. Visit http://www.dovepress.com/ testimonials.php to read real quotes from published authors. 